\title{
Group-specific Multi-allergen Sublingual/Swallow Immunotherapy Improves the Quality of Life of Polysensitized Children and Adults with Allergic Rhinitis
}

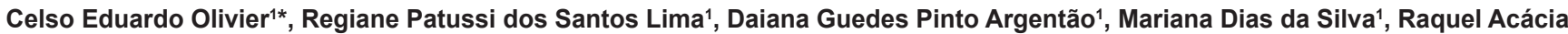
Pereira Gonçalves dos Santos², Marcus Pensuti² and Thaís Helena Piai-de-Morais ${ }^{2}$

${ }^{1}$ Instituto Alergoimuno de Americana, São Paulo, Brazil

${ }^{2}$ Faculty of Nursing, Anhanguera, University Santa Bárbara Unit, São Paulo, Brazil

\begin{abstract}
Background: The treatment of polysensitized allergic patients continues to represent a challenge and is a matter for debate amongst allergists who preferentially use allergen-specific immunotherapy.

Objective: To study the effect of group-specific sublingual/swallow immunotherapy on quality of life of polysensitized human subjects with allergic rhinitis diagnosed using a comprehensive panel of cutaneous tests.

Methods: 60 polysensitized subjects diagnosed with allergic rhinitis who submitted to group-specific sublingual/ swallow immunotherapy treatment corresponding to their cutaneous sensitizations, and who completed 6 months of treatment without the use of any complementary medication were evaluated with a validated quality of life questionnaire.

Results: There were significant improvements in all quality of life categories evaluated, which included: sleep, systemic symptoms, practical problems, nasal symptoms, eye symptoms, activities and emotions.

Conclusions: The administration of a group-specific multi-allergen sublingual/swallow immunotherapy as indicated by a comprehensive panel of sensitizing agents in cutaneous tests performed by a specialized team, significantly improved the quality of life of human polysensitized subjects with allergic rhinitis without the use of any additional medication.
\end{abstract}

Keywords: Allergen Immunotherapy; Child; Diagnosis; Hypersensitivity; Pepsin; Quality of life; Rhinitis

Abbreviations: SLIT: Sublingual/Swallow Immunotherapy; SIT: Subcutaneous Immunotherapy; GSM-SLIT: Group-Specific MultiAllergen SLIT; QOL: Quality of Life; NS-SLIT: Non-Specific MultiAllergen Sublingual/Swallow Immunotherapy

\section{Introduction}

To date, and since the 1970s, non-specific multi-allergen sublingual/ swallow immunotherapy (NS-SLIT) in Brazil has represented a cheap alternative approach for treating allergic diseases, and has been commonly prescribed by general practitioners [1]. This widespread use was encouraged by its low cost, easy administration, remarkable lack of collateral effects, prescription by brand name, extensive distribution (easily found in most drugstores) and broad allergen spectrum (composed of a comprehensive mixture of aerial, bacterial and food allergens). Usually, NS-SLIT was prescribed based entirely on clinical symptoms without a thorough etiological investigation and was associated with antihistamines/steroids. The lack of a graded concentration schedule and double-blinded placebo-controlled clinical trials, combined with the difficulty in recognizing the unequivocal presence/absence of benefits in this clinical context, explains why NS-SLIT was almost completely discredited by the Brazilian certified Allergy and Immunology specialists, despite the fact that some patients report amelioration of their symptoms with this treatment [1].

Subcutaneous immunotherapy (SIT), however, represents a longestablished treatment for respiratory allergies. Because the aggregation of many components into the composition of the SIT shots increases local cutaneous reactions [2], SIT is mandatorily allergen-specific and is given mainly to patients with monoallergy [3]. Therefore, most trials designed to compare sublingual/swallow immunotherapy (SLIT) with SIT use one or a limited number of allergens, despite the fact that the use of a large number of allergens does not increase the collateral effects of SLIT, as observed with the unique Brazilian NS-SLIT experience [1], and in the scientific literature that reports the safety profile of SLIT even in 3 years old children [4]. The treatment of polysensitized patients with the use of a single major allergen or multiple allergens is currently a matter of debate [5]. The clinical use of SLIT is based on the experimental observation that the most frequent outcome of an oral encounter with a soluble antigen is systemic tolerance [6,7]. The oral and intestinal mucosa are preferred sites for tolerogenic dendritic cells, which collect soluble antigens at the mucosal surface and migrate to the proximal draining submandibular/mesenteric lymph nodes and Peyer's patches. The tolerogenic dendritic cell will induce regulatory T-cells if this encounter occurs during a non-inflammatory response $[8,9]$. In addition to promoting allergen-specific desensitization, oral immunotherapy is able to prevent and reverse co-existent unrelated

*Corresponding author: Celso Eduardo Olivier, Instituto Alergoimuno de Americana, Rua Chile, 689, Bairro Cechino, Americana, São Paulo, Brazil, CEP 13465-740, Tel: +55 19 30122581/+55 19 34635941/+55 19 30324169; Fax: +55 19 34555726; E-mail: celso@alergoimuno.med.br/celso@docsystems.med.br; www.alergoimuno.med.br

Received July 13, 2013; Accepted August 19, 2013; Published August 24, 2013

Citation: Olivier CE, dos Santos Lima RP, Argentão DGP, da Silva MD, dos Santos RAPG, et al. (2013) Group-specific Multi-allergen Sublingual/Swallow Immunotherapy Improves the Quality of Life of Polysensitized Children and Adults with Allergic Rhinitis. J Allergy Ther 4: 148. doi:10.4172/2155-6121.1000148

Copyright: @ 2013 Olivier CE, et al. This is an open-access article distributed under the terms of the Creative Commons Attribution License, which permits unrestricted use, distribution, and reproduction in any medium, provided the original author and source are credited. 
Citation: Olivier CE, dos Santos Lima RP, Argentão DGP, da Silva MD, dos Santos RAPG, et al. (2013) Group-specific Multi-allergen Sublingual/ Swallow Immunotherapy Improves the Quality of Life of Polysensitized Children and Adults with Allergic Rhinitis. J Allergy Ther 4: 148. doi:10.4172/2155-6121.1000148

sensitizations by a cross-suppression mechanism [10]. The local and regional secretion of TGF- $\beta$ and IL-10 by tolerogenic dendritic cells and T-reg cells inside lymph nodes affects neighborings naïve T-cells and T-helper cells with diverse antigen specificities and induces them into an unspecific tolerogenic immune deviation [10-15].

Despite being widely used in several countries [16-19], SLIT is not officially approved by the American Food and Drug Administration, and the few clinics in America that have experience with SLIT employ the allergens approved for injection immunotherapy in an off-label manner [20,21], therefore most researchers studying the benefits of SLIT are based in Europe [22-24]. Despite the difference in administration approach, allergen-specific SLIT and SIT may be indirectly compared [25]. However, due to the difficulty associated with direct or indirect comparison with SIT in clinical trials, NS-SLIT is still an orphan therapy without sufficient evidence-based studies to define its advantages and/ or disadvantages in relation to the subcutaneous reference treatment.

To rationalize the clinical use of multi-allergen SLIT, we designed a protocol for a graded concentration schedule of group-specific multiallergen SLIT (GSM-SLIT) treatment inspired by the pioneers of allergy desensitization. The first GSM-SLIT treatment reported in the literature was performed in 1900 by Holbrook Curtis who used "drops" of a mixture of ragweed, ambrosia and golden rod to successfully treat seasonal "hay fever" patients sensitized to pollens of these and other plants [26]. Using a different approach than Curtis', we studied cutaneous sensitization using an extensive allergen panel of 46 extracts to establish 8 therapeutic groups consisting of combinations tailored to the subjects' sensitizations. The GSM-SLIT treatment was administered for 6 months, and the subjects who successfully completed the treatment without the additional use of any medication (steroids and/or antihistamines) were evaluated using a quality of life (QOL) questionnaire.

\section{Methods}

\section{Study design and subjects}

Two independent teams performed the diagnostic and treatment procedures (Instituto Alergoimuno de Americana) and QOL evaluations (Faculty of Nursing - Anhanguera University) in this open study. The study was approved by the ethical review board of the Anhanguera University (2442/2012), registered with the Brazilian clinical trial registry platform (CONEP 1038/2006) and was conducted according to the principles of the Declaration of Helsinki. The subjects' informed assent and consent were obtained before study enrolment, and their information was kept confidential. There were no financial or other potential conflicts of interest declared.

In total, 60 subjects ( 27 males) who completed 6 months of exclusive GSM-SLIT were interviewed. The mean age was 20.9 (SD \pm 16.4) years, including 23 children from 3 to 12 years.

The polysensitized subjects with allergic rhinitis were treated exclusively with one or more specific groups of sublingual/swallow allergens, according with their cutaneous sensitizations. All of the patients had previous clinical diagnoses of persistent rhinitis according to the ARIA criteria [27] and evidence of IgE-mediated hypersensitivity by both skin prick test and skin scrape test performed as previously described [28].

\section{Allergens extracts}

The diagnosis of sensitization and immunotherapy were performed with extracts purchased from the FDA Allergenic/Immunotech, Rio de Janeiro and clinically significant allergens found and extracted from Brazilian environment: Blomia tropicalis, Dermatophagoides pteronyssinus, Dermatophagoides farinae, Tyrophagus putrescentiae, Lepidoglyphus destructor, cat dander/hair, dog hair, feathers, lamb wool, Alternaria tenuis, Penicillium notatum, Aspergillus fumigatus, Poa pratensis, Lolium perenne, Cynodon dactylon, Achyrocline satureioides, Typha domingensis, Ceiba speciosa, Periplaneta americana, Culex $s p$, Aedes sp, Staphylococcus aureus, Staphylococcus epidermidis, Streptococcus pyogenes, Bos domesticus (milk and meat), Gallus domesticus (egg white, egg yolk and meat), Sus domesticus (meat), Penaeus brasiliensis (shrimp), Tilapia rendalli, parvalbumin (extracted from Tilapia rendalli by pepsin digestion), Hevea brasiliensis (latex sap directly extracted from trunk tree), cocoa (a mixture of pulp, roasted and unroasted cocoa beans), peanut, tomato, pineapple, banana, pear, peach, grape, cashew, papaya, coconut and soy (46 extracts).

\section{GSM-SLIT composition}

The allergens for GSM-SLIT were divided into 8 groups: a) mites; b) animal tegument; c) fungi; d) pollens; e) insects; f) bacterial allergens and toxoids; g) latex/latex-related food; and h) food unrelated to latex. The individual prescription of GSM-SLIT was determined according to the cutaneous reactivity pattern of skin tests. If there was at least one allergen reagent from a given group, all the constituents of this group were incorporated into the prescription. The groups prescribed were mixed in equal parts. The original extract concentration of each immunotherapeutic group was adjusted to $1 \mathrm{mg}$ of protein per $\mathrm{mL}$ as determined by colorimetric analysis, and 1:10 serial dilutions were derived from these adjusted solutions [29].

The food allergen immunotherapy was specifically composed of two main parts. The first part included a mixture of the antigens extracted from each food by Coca's solution. For this mixture, each extract was adjusted to $1 \mathrm{mg}$ of protein per $\mathrm{mL}$. The second part was composed of a digested mixture of each food extract in simulated gastric fluid with pepsin and $\mathrm{HCl}$ [30]. The objective was to provide the oral mucosa with peptides generated by gastric digestion which otherwise would not be able to reach the submandibular lymph nodes [31]. For simulated gastric digestion, the protein preparation was incubated with pepsin (Sigma-Aldrich, St Louis, Mo) in the proportion of $0.87 \mathrm{mg}$ pepsin to $1 \mathrm{mg}$ protein at $37^{\circ} \mathrm{C}$ with continuous agitation. The $\mathrm{pH}$ was titrated down to 2.0 with $0.1 \mathrm{~N} \mathrm{HCl}$ in 1 minute; the solution was then refrigerated, and the $\mathrm{pH}$ was titrated up with $0.1 \mathrm{~N} \mathrm{NaOH}$ to 7.0. The final concentration of the digested extract was adjusted to $1 \mathrm{mg} / \mathrm{mL}$ of food protein. The digestion of the individual extracts was examined by SDS-PAGE (Figure 1) as previously described [32]. The non-digested food extract solution $(1 \mathrm{mg} / \mathrm{mL}$ protein $)$ and the digested food extract solution $(1 \mathrm{mg} / \mathrm{mL}$ protein) were mixed at 1:1 volumes. The six-month treatment comprised 3 phases of two months each with treatment dilutions of 1:10.000, 1:1.000 and 1:100. The patient was oriented to put 3 drops under the tongue following teeth brushing, twice a day, to retain the solution in the mouth for approximately 5 minutes and then to swallow. The patient was also oriented to avoid eating or drinking anything for 20 minutes after the GM-SLIT administration.

In total, 49 subjects were treated with mite extract, 20 subjects with animal tegument extract, 33 subjects with fungi extract, 28 subjects with pollens extract, 15 subjects with insects extract, 12 subjects with bacterial and toxoids extracts, 24 subjects with latex/latex food related extract and 25 subjects with food extract not related to latex. The extracts were mixed in equal parts according to the subjects' individual sensitivities, as determined by skin tests, and were administered as a single therapy. 
Citation: Olivier CE, dos Santos Lima RP, Argentão DGP, da Silva MD, dos Santos RAPG, et al. (2013) Group-specific Multi-allergen Sublingual/ Swallow Immunotherapy Improves the Quality of Life of Polysensitized Children and Adults with Allergic Rhinitis. J Allergy Ther 4: 148. doi:10.4172/2155-6121.1000148

Page 3 of 6

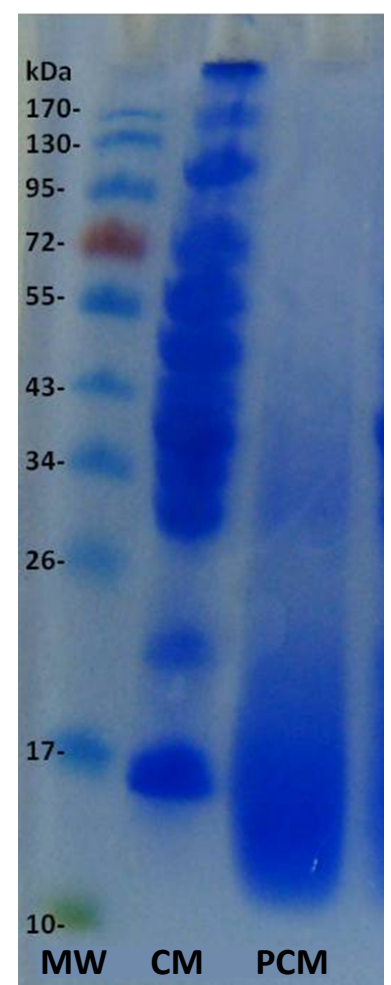

Figure 1: SDS-PAGE showing the molecular weight (MW) distribution of unmodified cow's meat extract proteins (CM) and pepsinized cow's meat extract (PCM)

\section{Quality of Life questionnaire}

An independent team (Faculty of Nursing-Anhanguera University) analyzed the outcome after six months of treatment by means of a QOL questionnaire specific for allergic rhinitis, adapted and validated for the Brazilian population [33,34]. The patient or responsible parent answered the same questionnaire twice, with the first concerning the QOL before the GSM-SLIT treatment and the second concerning the QOL after completion of 6 months of GSM-SLIT treatment. The patient was also checked for the correct use of GSM-SLIT and the absence of use of any medication for allergy (topical and/or systemic corticosteroids and/or antihistamines) during the 6 months period of GSM-SLIT treatment.

The QOL questionnaire represents seven categories: sleep, systemic symptoms, practical problems, nasal symptoms, eye symptoms, activities and emotions. The subject was presented with a zero to six points Likert scale. This scale attributed points to the intensity of symptoms with the answers quantified from 0 to 6 as follows: $0=\mathrm{I}$ did not feel discomfort, $1=$ disturbed me sometimes, $2=$ disturbed me few part of the time, $3=$ disturbed me moderately, $4=$ disturbed me many time, $5=$ disturbed me most of the time, and $6=$ disturbed me extremely all the time. The 27 individual questions (Q) were: Q1: Difficulty getting to sleep? Q2: Woke during the night? Q3: Lack of a good night's sleep? Q4: Fatigue? Q5: Thirst? Q6: Reduced productivity? Q7: Tired? Q8: Poor concentration? Q9: Headache? Q10: Worn out? Q11: Inconvenience of having to carry tissues or a handkerchief? Q12: Need to rub nose/eyes? Q13: Need to blow nose repeatedly? Q14: Stuffy nose? Q15: Runny nose? Q16: Itchy nose? Q17: Itchy eyes? Q18: Watery eyes? Q19: Photofobia? Q20: swelling eyelids? Q21: Performance on main activity? Q22: Performance on secondary activity? Q23: Performance on occasional activities? Q24: Frustration? Q25: Impatient? Q26: Irritable? and Q27: Embarrassed because of nasal symptoms?

\section{Statistical analyses}

The data were reported as the arithmetic mean with $95 \%$ confidence interval (CI). Comparisons between QOL index obtained before and after six months of GSM-SLIT were performed using a two-tailed paired t-test. The mean differences were considered significant at $\mathrm{p}<$ 0.05. Statistical analyses were performed using the GraphPad Prism for Windows (version 5.0; GraphPad Software, Inc., San Diego, CA, USA).

\section{Results} 16.8).

The mean number of reagent cutaneous tests was 15.2 (CI 13.5 to

The mean total QOL score of the entire group (Q1 to Q27) was 84.8 (CI 76.6 to 93.2) before GSM-SLIT and 24.1 (CI 19.2 to 28.9) after GSM-SLIT. The mean of the differences was 60.7 (CI 53.2 to 68.2) and this was significant for the paired t test $(\mathrm{p}<0.0001)$ Figure 2.

The mean QOL score of the sleep symptoms group (Q1 to Q3) was 10.25 (CI 8.7 to 11.7) before GSM-SLIT and 2.3 (CI 1.6 to 3.0) after GSM-SLIT. The mean of the differences was 7.9 (CI 6.5-9.3) and was significant for the paired $\mathrm{t}$ test $(\mathrm{p}<0.0001)$ (Figure 2).

The mean QOL score of the systemic symptoms group (Q4 to Q10) was 16.6 (CI 13.8 to 19.47) before GSM-SLIT and 5.6 (CI 3.9 to 7.3 ) after GSM-SLIT. The mean of differences was 11.0 (CI 8.7 to 13.2) and was significant for the paired $t$ test $(\mathrm{p}<0.0001)$ (Figure 2).

The mean QOL score of the practical problems group (Q11 to Q13) was 11.5 (CI 10.1 to 12.8 ) before GSM-SLIT and 3.3 (CI 2.5 to 4.1 ) after GSM-SLIT. The mean of the differences was 8.1 (CI 6.8 to 9.5) and was significant for the paired t test $(\mathrm{p}<0.0001)$ (Figure 2).

The mean QOL score of the nasal symptoms group (Q14 to Q16) was 12.9 (CI 11.7 to 14.9) before GSM-SLIT and 3.7 (CI 2.8 to 4.6) after GSM-SLIT. The mean of the differences was 9.2 (CI 7.9 to 10.5) and was significant for the paired $\mathrm{t}$ test $(\mathrm{p}<0.0001)$ (Figure 2).

The mean QOL score of the ocular symptoms group (Q17 to Q20) was 8.8 (CI 7.1 to 10.5) before GSM-SLIT and 2.7 (CI 1.8 to 3.6) after GSM-SLIT. The mean of the differences was 6.0 (CI 4.5 to 7.5$)$ and was significant for the paired $t$ test $(\mathrm{p}<0.0001)$ (Figure 2$)$.

The mean QOL score of the activities group (Q21 to Q23) was 10.4 (CI 8.9 to 11.8 ) before GSM-SLIT and 2.8 (CI 2.1 to 3.5) after GSM-SLIT. The mean of the differences was 7.5 (CI 6.3 to 8.7) and was significant for the paired test $(\mathrm{p}<0.0001)$ (Figure 2).

The mean QOL score of the emotions group (Q24 to Q27) was 14.5 (CI 12.8 to 16.2) before GSM-SLIT and 3.6 (CI 2.6 to 4.6) after GSMSLIT. The mean of the differences was 10.9 (CI 9.3 to 12.5) and was significant for the paired $\mathrm{t}$ test $(\mathrm{p}<0.0001)$ (Figure 2).

Of all individual questions, question 12 (need to rub nose/eyes) had a higher mean score before treatment (4.6) and after treatment (1.7). Question 19 (photophobia) had the lowest mean score before treatment (1.1) and after treatment (0.3). All individuals' questions had mean differences between pre-treatment and post-treatment answers that were significant for the paired $t$ test $(\mathrm{p}<0.05)$.

\section{Discussion}

Allergic rhinitis, a multifactorial disease with immune and non- 
Citation: Olivier CE, dos Santos Lima RP, Argentão DGP, da Silva MD, dos Santos RAPG, et al. (2013) Group-specific Multi-allergen Sublingual/ Swallow Immunotherapy Improves the Quality of Life of Polysensitized Children and Adults with Allergic Rhinitis. J Allergy Ther 4: 148. doi:10.4172/2155-6121.1000148
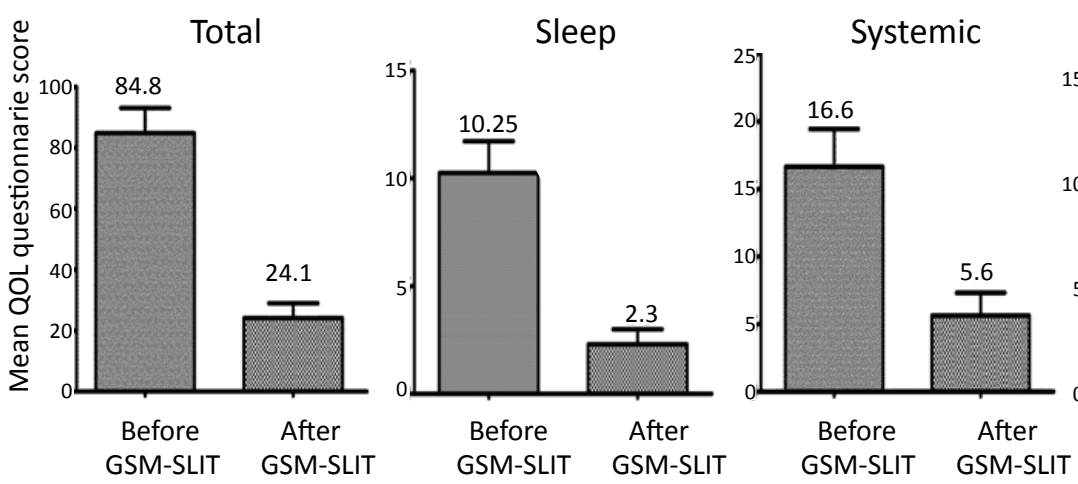

Practical
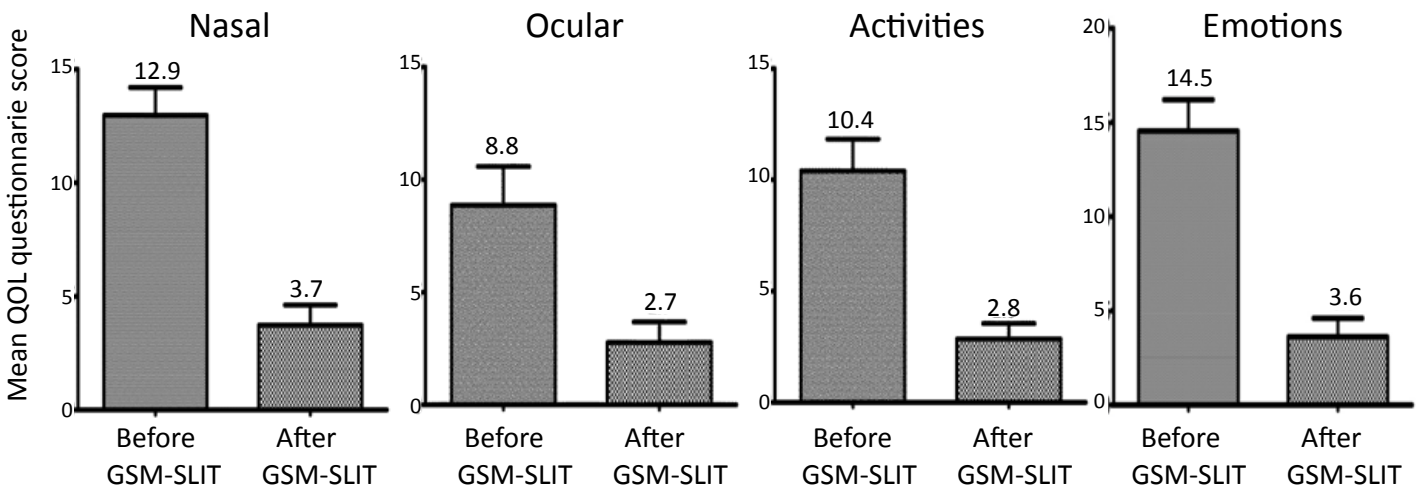

Figure 2: Box column graphs with $95 \% \mathrm{Cl}$ whiskers for the mean score from the (QOL) questionnaire (total and groups of questions) applied before and after group-specific allergen sublingual/swallow immunotherapy (GSM-SLIT) in 60 subjects with allergic rhinitis.

immune components, requires a multifactorial treatment. The etiologic diagnosis is itself therapeutic, if the knowledge of the causative allergens is a stimulus for the patient to avoid their particular triggers. However, environmental exposure is a variable factor that is difficult to control to avoid allergen inhalation. Equally difficult to control is the avoidance of oral antigen ingestion. Food allergies may produce respiratory symptoms [35]. Additionally, several airborne allergens also crossreact with food proteins as in the case of mite-shrimp-insects or fruitpollen-latex syndromes [36-38] and it is not uncommon to diagnose shrimp or fruit allergies in patients with mite-associated or polleninduced allergic rhinitis. In our study, the treatment of these conditions included the avoidance of those related food as well as group-specific immunotherapy.

Polysensitization is still a challenge to allergists who are used to dealing with allergen-specific immunotherapy [39]. Most physicians do not apply a comprehensive allergen panel for their diagnostic routine, so most sensitizations remain undiagnosed. The diagnosis of several sensitizations appears to be unnecessary if the previous intent is to treat the patient with an allergen-specific immunotherapy. However, even polysensitized patients treated with allergen-specific immunotherapy show improvements in their symptoms and this fact may be attributed to an unspecific action of allergen-specific immunotherapy. The offlabel use of allergen-specific immunotherapy to treat polysensitized patients seems to be driven by the lack of multi-allergen formulations approved for clinical use in the countries under the American Food and Drug Administration policies. This governmental restriction for multi- allergen immunotherapy may be justified when considering that the administration, by subcutaneous route, may be dangerous or hazardous to the patients, but the administration by sublingual/swallowing is relatively safe when prescribed with a progressive concentration schedule under specialized medical supervision. In addition to safety, there are other advantages in prescribing allergen immunotherapy orally, particularly if it is administered as part of a tolerance-induction strategy. The administration of an antigen by the oral route diminishes its further absorption [40]. This immune exclusion is mediated mainly by IgA which induces specific systemic tolerance. The oral mucosa is a privileged site for inducing tolerogenesis [41], but usually the oral mucosa is naturally provided only with large undigested proteins. Incomplete gastrointestinal digestion may generate immunogenic peptides devoid of their mediator-releasing activity, but not $\mathrm{T}$ cellactivating properties [42]. Tolerance-induction strategies may include homologous unmodified allergens associated with their modified forms [43]. The administration of intact proteins together with the peptides resulting from their peptic digestion diminishes the sensitizing capacity of oral allergens [44]. Tropomyosin, for instance, is the common allergen of cockroaches, mites and shrimps and is found in mammalian meat, therefore, it is reasonable to assume that their peptic digestion may produce similar peptides. If these peptides contain the same linear epitopes presented to $\mathrm{T}$ cell receptors by the antigen presenting cells, they can potentially induce cross-suppression when administered within a tolerance-induction strategy [45]. However, unless these peptides reach the oral mucosa by gastroesophageal regurgitation, they 
Citation: Olivier CE, dos Santos Lima RP, Argentão DGP, da Silva MD, dos Santos RAPG, et al. (2013) Group-specific Multi-allergen Sublingual/ Swallow Immunotherapy Improves the Quality of Life of Polysensitized Children and Adults with Allergic Rhinitis. J Allergy Ther 4: 148. doi:10.4172/2155-6121.1000148

Page 5 of 6

will be targeted by gut immune cells only if not previously digested by pancreatic trypsin and microvilli peptidases. Thus, as part of the induction-tolerance strategy and to provide additional peptides directly to the oral mucosa (where they will not be digested by trypsin and peptidases), we pepsinized an aliquot of each food extract and added this mixture to food GSM-SLIT [46,47].

The treatment of allergic conditions is not based on specific interventions, but on global strategies involving educational guidelines, antihistamine/anti-inflammatory/symptomatic drugs and a desensitizing immunotherapy based on a thorough diagnosis (syndromic, anatomical and etiological). Despite the efficacy of these measures, which could be accessed by several biological markers, what really counts for the patient is to be free of the symptoms and released of the use of medications associated with collateral effects. Most subjects enrolled in this study had previously been treated with conventional therapies (nasal steroids and antihistamines) without satisfactory improvement of their symptoms, therefore, they were comfortable with the idea of the exclusive use of GSM-SLIT. The QOL questionnaire represents the resulting of the overall toleranceinduction strategy over these subjects and cannot differentiate between the influence of environmental control, dietary avoidance and GSMSLIT. As the three pillars of this treatment act synergistically, they were prescribed together and resulted in a pronounced improvement in the QOL as demonstrated by the questionnaires scores. The conclusion of this study is that polysensitized patients with allergic rhinitis diagnosed using cutaneous tests by a specialized team may be safely and effectively treated with GSM-SLIT without the concomitant use of any medication.

\section{Acknowledgments}

All authors contributed to the literature search and the study design. The preparation of allergens extracts was performed by RPSL and DGPA. The preparation of immunotherapy was performed by MDS. Cutaneous tests were performed by RPSL and DGPA under the medical supervision of CEO who prescribed and supervised the GSM-SLIT. QOL interviews were performed/ supervised by RAPGS, MP and THPM who analyzed the raw data. The database was fully provided to CEO who had the final responsibility for the decision to submit the manuscript for publication and drafted the initial report. All of the co-authors revised the report and approved the final version. The American Journal Experts edited the English grammar.

\section{Funding Source}

Olivier CE, Argentão DGP, Lima RPS and Silva MD received grant support from Instituto Alergoimuno de Americana.

Piai-de-Morais TH, Pensuti M and Santos RAPG received grant support from Faculty of Nursing - Anhanguera University.

\section{Ethical Approval}

The study was approved by the ethical review board of the Anhanguera University (2442/2012) registered at the Brazilian clinical trial registry platform (CONEP 1038/2006) and conducted according to the principles of the Declaration of Helsinki.

\section{References}

1. Camões S, Mendonça I, Marinho JB (1971) Treatment for desensitizing allergic disorders associated with oral epsilon aminocaproic acid. Patologia Geral (Brazil) 56: 87-93.

2. Calabria CW, Coop CA, Tankersley MS (2008) The GILL study: glycerin-induced local reactions in immunotherapy. J Allergy Clin Immunol 121: 222-226.

3. Akdis CA, Blaser K, Akdis M (2004) Apoptosis in tissue inflammation and allergic disease. Curr Opin Immunol 16: 717-723.

4. Fiocchi A, Pajno G, La Grutta S, Pezzuto F, Incorvaia C, et al. (2005) Safety of sublingual-swallow immunotherapy in children aged 3 to 7 years. Ann Allergy Asthma Immunol 95: 254-258.

5. Calderon MA, Cox L, Casale TB, Moingeon P, Demoly P (2012) Multipleallergen and single-allergen immunotherapy strategies in polysensitized patients: looking at the published evidence. J Allergy Clin Immunol 129: 929934

6. Strobel S, Mowat AM (1998) Immune responses to dietary antigens: oral tolerance. Immunol Today 19: 173-181.

7. Besredka A (1909) De l'anaphylaxie. Sixiéme memoire de l'anaphylaxie lactique. Ann Inst Pasteur 23: 166-174.

8. Akdis CA, Barlan IB, Bahceciler N, Akdis M (2006) Immunological mechanisms of sublingual immunotherapy. Allergy 61: 11-14.

9. Allam JP, Würtzen PA, Reinartz M, Winter J, Vrtala S, et al. (2010) Phl p 5 resorption in human oral mucosa leads to dose-dependent and time-dependen allergen binding by oral mucosal Langerhans cells, attenuates their maturation, and enhances their migratory and TGF-beta1 and IL-10-producing properties. J Allergy Clin Immunol 126: 638-645.

10. Vaz NM, Maia LC, Hanson DG, Lynch JM (1981) Cross-suppression of specific immune responses after oral tolerance. Mem Inst Oswaldo Cruz 76: 83-91.

11. Mowat AM (2003) Anatomical basis of tolerance and immunity to intestinal antigens. Nat Rev Immunol 3: 331-341.

12. Mowat AM, Parker LA, Beacock-Sharp H, Millington OR, Chirdo F (2004) Ora tolerance: overview and historical perspectives. Ann N Y Acad Sci 1029: 1-8.

13. Bohle B, Kinaciyan T, Gerstmayr M, Radakovics A, Jahn-Schmid B, et al (2007) Sublingual immunotherapy induces IL-10-producing T regulatory cells, allergen-specific T-cell tolerance, and immune deviation. J Allergy Clin Immuno 120: $707-713$.

14. Pajno GB, Barberio G, De Luca F, Morabito L, Parmiani S (2001) Prevention of new sensitizations in asthmatic children monosensitized to house dust mite by specific immunotherapy. A six-year follow-up study. Clin Exp Allergy 31: 13921397.

15. Steinman RM, Hawiger D, Nussenzweig MC (2003) Tolerogenic dendritic cells. Annu Rev Immunol 21: 685-711.

16. Potter $P$ (2013) Sublingual immunotherapy in southern Africa: Lessons learned. J Allergy Clin Immunol 132: 99-100.

17. Rodríguez Santos O (2008) [Sublingual immunotherapy in allergic rhinitis and asthma in 2-5 year-old children sensitized to mites]. Rev Alerg Mex 55: 71-75.

18. Cagnani CE, Lockey RF, Passalacqua G, Canonica GW (2008) [Immunotherapy in Latin America. From the past to the future]. Rev Alerg Mex 55: 33-37.

19. Park IH, Hong SM, Lee HM (2012) Efficacy and safety of sublingual immunotherapy in Asian children. Int J Pediatr Otorhinolaryngol 76: 1761-1766.

20. Lin SY, Leatherman B (2011) Sublingual immunotherapy. Otolaryngol Clin North Am 44: 753-764.

21. Morris MS, Lowery A, Theodoropoulos DS, Duquette RD, Morris DL (2012) Quality of life improvement with sublingual immunotherapy: a prospective study of efficacy. J Allergy (Cairo) 2012: 253879.

22. Cox L, Wallace D (2011) Specific allergy immunotherapy for allergic rhinitis: subcutaneous and sublingual. Immunol Allergy Clin North Am 31: 561-599.

23. Passalacqua G, Compalati E, Canonica GW (2011) Sublingual immunotherapy for allergic rhinitis: an update. Curr Opin Otolaryngol Head Neck Surg 19: 4347.

24. Ciprandi G, Cadario G, Di Gioacchino GM, Gangemi S, Gasparini A, et al. (2010) Sublingual immunotherapy in children with allergic polysensitization. Allergy Asthma Proc 31: 227-231

25. Dretzke J, Meadows A, Novielli N, Huissoon A, Fry-Smith A, et al. (2013) Subcutaneous and sublingual immunotherapy for seasonal allergic rhinitis: a systematic review and indirect comparison. J Allergy Clin Immunol 131: 13611366

26. Curtis $\mathrm{H}$ (1902) The immunization treatment of hay fever. JAMA 39: 1267-1268.

27. Bousquet J, Khaltaev N, Cruz AA, Denburg J, Fokkens WJ, et al. (2008) Allergic Rhinitis and its Impact on Asthma (ARIA) 2008 update (in collaboration with the World Health Organization, GA(2)LEN and AllerGen). Allergy 63: 8-160.

28. Olivier CE, Argentão DGP, Santos RAPG, Silva MD, Lima RPS, et al. (2013) Skin Scrape Test: An Inexpensive and Painless Skin Test for Recognition of Immediate Hypersensitivity in Children and Adults. Open Allergy J 6: 9-17. 
Citation: Olivier CE, dos Santos Lima RP, Argentão DGP, da Silva MD, dos Santos RAPG, et al. (2013) Group-specific Multi-allergen Sublingual/ Swallow Immunotherapy Improves the Quality of Life of Polysensitized Children and Adults with Allergic Rhinitis. J Allergy Ther 4: 148. doi:10.4172/2155-6121.1000148

Page 6 of 6

29. Hartree EF (1972) Determination of protein: a modification of the Lowry method that gives a linear photometric response. Anal Biochem 48: 422-427.

30. Untersmayr E, Poulsen LK, Platzer MH, Pedersen MH, Boltz-Nitulescu G, et al. (2005) The effects of gastric digestion on codfish allergenicity. J Allergy Clin Immunol 115: 377-382.

31. Mackenzie KJ, Fitch PM, Leech MD, Ilchmann A, Wilson C et al. (2012) Combination peptide immunotherapy based on T-cell epitope mapping reduces allergen-specific $\mathrm{IgE}$ and eosinophilia in allergic airway inflammation. Immunology 138: 258-268.

32. Olivier CE, Lorena SL, Pavan CR, dos Santos RA, dos Santos Lima RP, et al. (2012) Is it just lactose intolerance? Allergy Asthma Proc 33: 432-436.

33. Juniper EF, Guyatt GH (1991) Development and testing of a new measure of health status for clinical trials in rhinoconjunctivitis. Clin Exp Allergy 21: 77-83.

34. Nascimento Silva M, Naspitz C, Solé D (2001) Evaluation of quality of life in children and teenagers with allergic rhinitis: adaptation and validation of the Rhinoconjunctivitis Quality of Life Questionnaire (RQLQ). Allergol Immunopathol (Madr) 29: 111-118

35. Olivier CE (2013) Food Allergy. J Aller Ther S3:004. [doi: 10.4172/2155-6121. S3-004]

36. Santos AB, Chapman MD, Aalberse RC, Vailes LD, Ferriani VP, et al. (1999) Cockroach allergens and asthma in Brazil: identification of tropomyosin as a major allergen with potential cross-reactivity with mite and shrimp allergens. J Allergy Clin Immunol 104: 329-337.

37. Wang J, Calatroni A, Visness CM, Sampson HA (2011) Correlation of specific $\lg \mathrm{E}$ to shrimp with cockroach and dust mite exposure and sensitization in an inner-city population. J Allergy Clin Immunol 128: 834-837.

38. Díez-Gómez ML, Quirce S, Cuevas M, Sánchez-Fernández C, Baz G, et al. (1999) Fruit-pollen-latex cross-reactivity: implication of profilin (Bet $\vee 2$ ). Allergy 54: $951-961$
39. Ciprandi G, Incorvaia C, Puccinelli P, Soffia S, Scurati S, et al. (2011) Polysensitization as a challenge for the allergist: the suggestions provided by the Polysensitization Impact on Allergen Immunotherapy studies. Expert Opin Biol Ther 11: 715-722.

40. Swarbrick ET, Stokes CR, Soothill JF (1979) Absorption of antigens after ora immunisation and the simultaneous induction of specific systemic tolerance. Gut 20: 121-125.

41. Mascarell L, Lombardi V, Louise A, Saint-Lu N, Chabre H, et al. (2008) Ora dendritic cells mediate antigen-specific tolerance by stimulating $\mathrm{TH} 1$ and regulatory CD4+ T cells. J Allergy Clin Immunol 122: 603-609.

42. Schimek EM, Zwölfer B, Briza P, Jahn-Schmid B, Vogel L, et al. (2005) Gastrointestinal digestion of Bet $v$ 1-homologous food allergens destroys their mediator-releasing, but not T cell-activating, capacity. J Allergy Clin Immunol 116: $1327-1333$

43. Olivier CE, Lima RP, Pinto DG, Santos RA, Silva GK, et al. (2012) In search of a tolerance-induction strategy for cow's milk allergies: significant reduction of beta-lactoglobulin allergenicity via transglutaminase/cysteine polymerization. Clinics (São Paulo) 67: 1171-1179.

44. Bøgh KL, Barkholt V, Madsen CB (2013) The sensitising capacity of intact $\beta$ -lactoglobulin is reduced by co-administration with digested $\beta$-lactoglobulin. In Arch Allergy Immunol 161: 21-36.

45. Cortellini G, Spadolini I, Santucci A, Cova V, Conti C, et al. (2011) Improvement of shrimp allergy after sublingual immunotherapy for house dust mites: a case report. Eur Ann Allergy Clin Immunol 43: 162-164.

46. Kulis M, Macqueen I, Li Y, Guo R, Zhong XP, et al. (2012) Pepsinized cashew proteins are hypoallergenic and immunogenic and provide effective immunotherapy in mice with cashew allergy. J Allergy Clin Immunol 130: 716723.

47. Järvinen KM (2013) Allergy prevention via co-administration of intact food allergen and its epitope soup? Int Arch Allergy Immunol 161: 195-196. 